\title{
Collateral sprouting axons of end-to-side nerve coaptation in the avulsion of ventral branches of the C5-C6 spinal nerves in the brachial plexus
}

\author{
Paweł Reichert ${ }^{1}$, Zdzisław Kiełbowicz ${ }^{2}$, Piotr Dzięgiel ${ }^{3}$, Bartosz Puła $^{3}$, Jan Kuryszko ${ }^{4}$, Marcin Wrzosek $^{5}$, \\ Maciej Kiełbowicz ${ }^{2}$, Jerzy Gosk ${ }^{1}$ \\ ${ }^{1}$ Department of Traumatology, Clinic of Traumatology and Hand Surgery, Wroclaw Medical University, Wrocław, ${ }^{2}$ Department \\ of Surgery, Faculty of Veterinary Medicine, Wroclaw University of Environmental and Life Sciences, Wrocław, ${ }^{3}$ Department of Histology \\ and Embryology, Wroclaw Medical University, Wrocław, ${ }^{4}$ Department of Animal Physiology and Biostructure, Faculty of Veterinary \\ Medicine, Wroclaw University of Environmental and Life Sciences, Wrocław, ${ }^{5}$ Department of Internal Medicine and Clinic of Diseases \\ of Horses, Dogs and Cats, Faculty of Veterinary Medicine, Wroclaw University of Environmental and Life Sciences, Wrocław, Poland
}

\begin{abstract}
Introduction: This study assessed the collateral sprouting in avulsion of the ventral branches of the C5 and C6 spinal nerves treated by coaptation of these nerves to the $C 7$ spinal nerve on the brachial plexus of rabbits.

Material and methods: Thirty-six New Zealand rabbits were randomly divided into four groups: end-to-side coaptation (ESN) $(n=12)$, side-to-side coaptation (SSN) $(n=12)$, direct neurorrhaphy (end-to-end) $(E E N)(n=6)$ and no coaptation $(n=6)$. The operations were performed on the left brachial plexus. The contralateral, non-operated right brachial plexi were used as the control group. The groups were compared using morphological, electrophysiological and behavioral methods. The follow-up duration was 20 weeks.

Results: Significant differences were observed in all parameters when the experimental groups were compared with the control group and the no coaptation group. The histology of axonal regeneration after ESN, but not after SSN, was comparable to that after EEN. There were no significant differences in the electrophysiological, behavioral assessment or G-ratio parameters between the ESN and EEN groups. There were significant differences in the behavioral assessment, G-ratio and the histomorphometric parameters between the SSN and EEN groups, which disagreed with the electrophysiological results. Sensory axon collateral sprouting was more rapid than motor axon collateral sprouting. Conclusions: The electrophysiological, histomorphometric and behavioral results obtained using end-to-side coaptation of ventral branches of the $C 5$ and $C 6$ spinal nerves to the $C 7$ spinal nerve in the brachial plexi of rabbits confirm the occurrence of collateral sprouting at this level. After further research is performed to confirm the results of this study, end-to-side coaptation might emerge as an alternative method in the treatment of brachial plexus avulsion.
\end{abstract}

Key words: collateral sprouting, spinal nerves, brachial plexus, coaptation. 


\section{Introduction}

The most commonly injured sites in the brachial plexus include the ventral branches of the C5 and C6 spinal nerves and the upper trunk $[9,41]$. Indeed, most brachial plexus lesions are observed in the supraclavicular area rather than the infraclavicular area. Of these supraclavicular injuries, brachial plexus avulsions are present in $75 \%$ of cases [41].

This type of damage cannot be repaired by classical methods, such as "end-to-end" suture with the use of autogenous nerve grafts. Currently, a neurotization procedure is performed [9], in which the intercostal nerve [16], accessory nerve [2], branches of the ipsilateral cervical plexus [11,46], phrenic nerve [26], contralateral C7 [14,26] nerve, selective ulnar nerve to the musculocutaneous nerve [36] and hypoglossal nerve [42] may be used as donor nerves. In such cases, the distal stump of the damaged nerve is sutured to the proximal stump of the donor nerve by direct neurorrhaphy (end-to-end). Unfortunately, donor function is lost when this procedure is performed.

A potential alternative procedure is nerve coaptation, in which the distal stump of the transected nerve is sutured to an undamaged donor nerve via end-to-side coaptation. Efficacy of sensory and motor collateral sprouting after end-to-side coaptation has been confirmed by retrograde double labeling $[10,35,37,47,58,59]$.

Studies have shown that coaptation is more effective when motor axons are coapted to other motor axons [48], when sensory axons are coapted to other sensory axons [33] or when the donor and recipient axons are derived from an identical region of the spinal cord. The results are difficult to predict when mixed nerves are used as donors [29,30,43].

Most previous studies of experimental coaptation have been performed on rats, and these studies have involved the use of long branches of the brachial [47] and lumbar plexus of the peripheral nervous system [34]. The tibial nerve is most often coapted to the peroneal or sural nerve [18], and the ulnar nerve is most frequently coapted to the musculocutaneous nerve [47].

In the rabbit brachial plexus, the ventral branches of the C5 and C6 spinal nerves form the caudal trunk, which creates the suprascapular nerve. The exclusive innervation of the supraspinatus and infraspinatus muscles by the suprascapular nerve and the easy access to these muscles and dermatomes in rab- bits might indicate that these animals are a reliable model to use for studying the functions of the C5-C6 spinal nerves. Such innervations provide us with an opportunity to evaluate the recovery of nerve function after coaptation in high brachial plexus injuries.

Due to recent encouraging results coupled with the overall lack of experimental studies examining injuries to the ventral branches of the spinal nerves and brachial plexus trunks, we aimed to evaluate and confirm the treatment efficacies of end-to-side and side-to-side coaptation of the ventral branches of the C5 and C6 spinal nerves to the C7 spinal nerve in brachial plexus avulsion using an experimental rabbit model.

\section{Material and methods \\ Experimental model}

The experiments were approved by the Second Local Ethics Committee for Animals of the University of Life Sciences in Wroclaw. All rabbits (22 weeks old with an average weight of $3.6 \mathrm{~kg}$ ) were treated using the same anesthesia protocol. Premedication was performed using medetomidine (Cepetor) at a dose of $150 \mu \mathrm{g} / \mathrm{kg}$ body weight, butorphanol (Torbugesic) at a dose of $0.2 \mathrm{mg} / \mathrm{kg}$ body weight and ketamine (Bioketan) at a dose of $35 \mathrm{mg} / \mathrm{kg}$ body weight. General anesthesia was performed with propofol, which was administered continuously at a dose of $0.1 \mathrm{mg} /$ $\mathrm{kg} / \mathrm{min}$. The analgesic effect was supported by fentanyl at a dose of $2-3 \mu \mathrm{g} / \mathrm{kg}$. After the procedure, buprenorphine (Vetergesic) was used at a dose of $20 \mu \mathrm{g} / \mathrm{kg}$ i.m. every $8 \mathrm{~h}$. The animals were administered meloxicam (Metacam) at $0.2 \mathrm{mg} / \mathrm{kg}$ body weight for two days after surgery. They were operated on in the lateral position, and the mean duration of surgery was approximately 26 min.

Adequate care was taken to minimize pain and discomfort during and after the operations. The follow-up duration was 20 weeks.

\section{Experimental design}

A total of 36 New Zealand rabbits were randomly divided into the following four groups: end-to-side coaptation (ESN) $(n=12)$, side-to-side coaptation $(\mathrm{SSN})(n=12)$, direct neurorrhaphy (end-to-end) $(\operatorname{EEN})(n=6)$ and no coaptation $(n=6)$. The operations were performed on the left brachial plexus. The contralateral, non-operated right brachial plexi of the rabbits were used as the control group. The groups 
were compared using morphological, electrophysiological and behavioral methods. The follow-up duration was 20 weeks.

\section{Surgical procedure}

The experimental procedures were performed on the left brachial plexus using a lateral approach (Fig. 1). All of the collateral branches of the C5, C6/ caudal truncus and C7 spinal nerves were transected.

The ventral branches of the $\mathrm{C} 5$ and $\mathrm{C} 6$ nerves were avulsed, and then the distal stumps were incised. An epineural window was created on the cranial side of the C7 spinal nerve for coaptation. For side-to-side coaptation, supplemental epineural windows were created on the caudal sides of the $\mathrm{C} 5$ and $\mathrm{C} 6$ spinal nerves. End-to-side or side-toside neurorrhaphy was then performed between the distal stumps of these nerves and the windows by placing two stitches (Ethilon 10-0) in the C7 spinal nerve. To perform direct neurorrhaphy (end-to-end), we sutured two stitches (Ethilon 10-0). In the group without coaptation, we resected $2 \mathrm{~cm}$ of the $C 5$ and C6 spinal nerves, and the distal stump was inserted into soft tissue. Then, the skin was sutured with 4-0 sutures. After 20 weeks, the left and right brachial plexi were exposed to obtain sample nerves. The animals were euthanized by pentobarbital intravenous injection (Morbital).

\section{Electrophysiological analysis}

The animals were anesthetized by intramuscular injections of medetomidine (dose: $0.5 \mathrm{mg} / \mathrm{kg}$ ), butorphanol $(0.1 \mathrm{mg} / \mathrm{kg})$ and ketamine $(25 \mathrm{mg} / \mathrm{kg})$ for electromyographic examination.
A

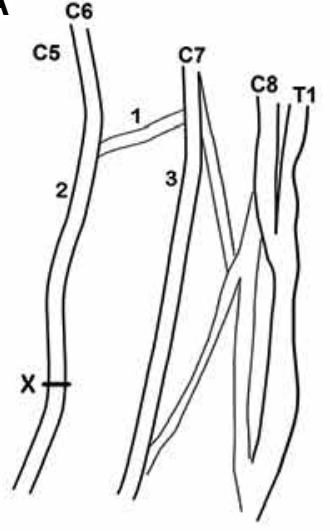

B

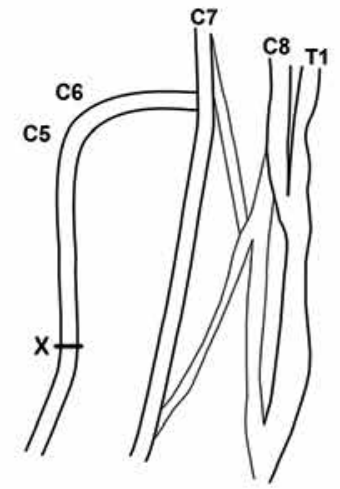

C
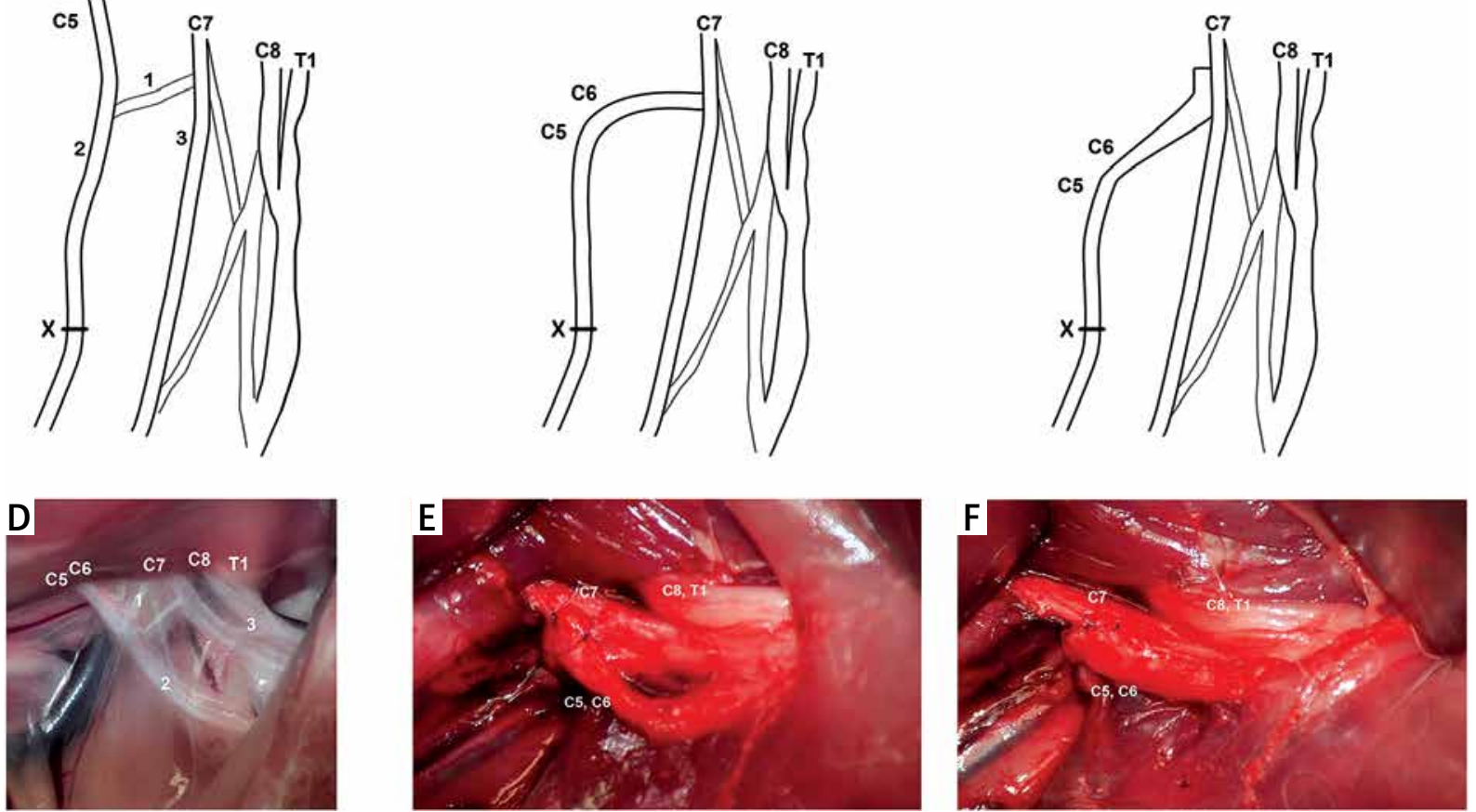

Fig. 1. Intraoperative image and schematic illustration of the surgical picture in each group. A) Schematic illustration showing the macroscopic structure of the rabbit's right brachial plexus. C5 - ventral branch of the C5 spinal nerve, C6 - ventral branch of the C6 spinal nerve, C7 - ventral branch of the C7 spinal nerve, C8 - ventral branch of the C8 spinal nerve, Th1 - ventral branch of the Th1 spinal nerve. B) Schematic illustration of end-to-side coaptation of C5 and C6 to C7. C) Schematic illustration of side-to-side coaptation of C5 and C6 to C7. D) Surgical photograph. Macroscopic structure of the rabbit's right brachial plexus. C5, C6, C7, C8, Th1 - ventral branches of the spinal nerves: C5-Th1, 1 - connection branches, 2 - cranial trunk, 3 - caudal trunk. E) Surgical photograph. End-to-side coaptation of C5 and C6 to C7. Neurorrhaphy by the epineural window. F) Surgical photograph. Side-to-side coaptation of C5 and C6 to C7. Neurorrhaphy by the epineural window joining the lateral part of $\mathrm{C} 5$ and $\mathrm{C} 6$ with the medial part of $\mathrm{C} 7 . \mathrm{X}$ - position of nerve sample. 
This examination was performed after 20 weeks at an ambient temperature of $22^{\circ} \mathrm{C}$ using Nicolet Viking Quest portable electrodiagnostic equipment, version 11.0 (Nicolet Biomedical, Madison, WI, USA). A standard electromyographic concentric needle electrode (used as an active and recording electrode) and a subdermal monopolar ground electrode were used in this study. Electromyography (EMG) was performed by intramuscular insertions of the electrodes into the following muscles: the supraspinatus (innervated by the suprascapular nerve, C5-C6), the infraspinatus (innervated by the suprascapular nerve, C5-C6), the subscapularis (innervated by the subscapular nerve, (6-C8), and the biceps brachii (innervated by the musculocutaneous nerve, C5-C7). During EMG, insertional activity was assessed. Pathological discharge, if present, was recorded and evaluated to determine the type, frequency, duration and amplitude according to a semi-quantitative numerical scale modified by Kimura [31] (Table I). Higher values indicated a lower degree of muscle innervation.

\section{Histomorphometric analysis of sampled nerves}

The nerve specimens were immersion-fixed in $2.5 \%$ glutaraldehyde for $12 \mathrm{~h}$ at $4^{\circ} \mathrm{C}$ and were then washed with cacodylate buffer (Serva, Heidelberg, Germany). Next, the specimens were post-fixed for $1 \mathrm{~h}$ in $1 \%$ osmium tetroxide (dissolved in cacodylate buffer), washed with cacodylate buffer, dehydrated in alcohol and embedded in Epon (Chempur, Piekary Slaskie, Poland). A Power Tome XL (RMC Products, Tucson, AZ, USA) was used to cut the fixed nerve specimens into 0.6- $\mu$ m-thick sections, which were stained with toluidine blue (Serva) and mounted using Euparal (Roth, Mannheim, Germany).

Table I. A modified semi-quantitative numerical scale for the electromyographic evaluation of the degree of muscle denervation

\begin{tabular}{|cl|}
\hline 0 & No pathological potentials \\
\hline 1 & Very rare denervation potentials \\
\hline 2 & $\begin{array}{l}\text { Sporadic pathological activity, recorded in two or more } \\
\text { places }\end{array}$ \\
\hline 3 & $\begin{array}{l}\text { Frequent pathological activity, recorded regardless } \\
\text { of the position of the needle electrode }\end{array}$ \\
\hline 4 & $\begin{array}{l}\text { Abundant pathological activity, recorded regardless } \\
\text { of the position of the needle electrode }\end{array}$ \\
\hline
\end{tabular}

The stained nerve cross sections were analyzed under a BX41 light microscope equipped with the CellD computer-assisted image analysis program (Olympus, Tokyo, Japan). For analysis, photomicrographs at $\times 630$ magnification were obtained manually without overlap of the microscopic fields. In each nerve cross section, the minimal diameters of the axons and nerve fibers (axon and adjacent myelin) were measured. Only circular-shaped fibers were measured, which allowed for calculation of the myelin sheath thicknesses of the nerve fibers using the following formula: myelin sheath thickness = nerve fiber diameter - axon diameter. The degree of myelination was evaluated using the G-ratio (the ratio of the minimal diameters of the axon and fiber) [45]. Additionally, the myelin sheath and myelinated fiber densities were determined. At least 200 nerve fibers were analyzed per animal. The materials used for histological examination were collected at identical heights of $2 \mathrm{~cm}$ per anastomosis in the experimental groups and $4 \mathrm{~cm}$ from the spinal canal in the control group.

\section{Skin pinch test}

The skin pinch test was performed to determine the return of sensory capacity by examining nociception [33]. The skin of the animals was gently pinched with forceps (in 3-mm intervals) until the first signs of discomfort were noticed, including lifting of the limbs, turning of the head or trembling of the skin. The healthy limb and the limb with nerve coaptation were examined to record a normal reaction to stimulation. We focused on the dermatomes innervated by nerves derived from $\mathrm{C} 5, \mathrm{C} 6$, and $\mathrm{C} 7$. This test was performed at 1 day after surgery and at 4, 8, 12, 16, and 20 weeks after surgery. For this study, we used the following 4-point grading scale: 0 - no response; 1 - mild response, the animal presents a very weak reaction; 2 - moderate response, the animal shows a reaction in response to stimuli; and 3 - the animal exhibits a significant response to stimuli.

\section{Nerve pinch test}

To assess the statuses of nociceptive axons, the nerve pinch test was performed $[33,37]$. This test was conducted before euthanasia, when the animals were lightly anesthetized. The EEN, ESN, and SSN sites were carefully dissected from nearby tissue. A series of pinches were then delivered to the recipient caudal trunk/suprascapular nerve with fine- 
tipped forceps, proceeding in millimeter increments in the distal-to-proximal direction. The area of the suprascapular nerve stump at which a pinch first elicited the animal's reflexive withdrawal response (a positive pinch test) was recorded, and its distance from the site of the end-to-side or side-to-side coaptation was measured. The pinching of the recipient caudal trunk/suprascapular nerve stump was always stopped at least $15 \mathrm{~mm}$ distal from the site of coaptation, thus preserving the remainder of the caudal trunk/suprascapular nerve for use as a histopathological sample.

\section{Modified grooming test}

A test for assessing the muscle power of rat forelimbs [34], conducted to ascertain whether and when a reconnected nerve became functional, was adopted for use in rabbits. The test consisted of spraying water over the animal's face to provoke grooming movements of the forepaws toward the head. During normal grooming, the animals raise both forelimbs, lick them and reach behind the ears. The grooming response was graded from 0 to 5 as follows: 0 - no response; 1 - flexion at the elbow, not reaching the snout; 2 - flexion reaching the snout; 3 - flexion reaching below the eyes; 4 - flexion reaching the eyes; and 5 - flexion reaching the ears and beyond. The animals were tested at 4, 8, 12, 16, and 20 weeks following surgery.

\section{Statistical analysis}

The data were analyzed using Prism statistical software, version 5.0 (GraphPad, La Jolla, CA, USA). Student's $t$-test for independent samples was performed to compare the significance of the changes between the groups. The Mann-Whitney $U$ test was used for non-parametric values. The distribution of the data was tested by the Shapiro-Wilk test. Dissimilarities between the groups were examined using the non-parametric Kruskal-Wallis test with Dunn's post hoc analysis. Differences were considered significant at a $p<0.05$ for Student's $t$-test and at $p<0.01$ for the Mann-Whitney $U$ test.

\section{Results}

\section{Electromyographic analysis}

Electromyographic examination revealed the presence of denervation potentials in the ESN, SSN, and
EEN groups ( $\mathrm{A}$ - experimental groups) and in the no coaptation group (B) and did not reveal any pathological myoelectric activity in the control group (C).

Most of the changes in the ESN group were found in the infraspinatus muscle, with a mean value of $2.08 \pm 0.64$, followed by the supraspinatus $(1.54 \pm$ $0.78)$, biceps $(1.54 \pm 0.78)$ and subscapularis muscles $(1.38 \pm 0.77)$. The results were dominated by changes in grades 1 and 2 denervation, as graded using the Kimura scale.

The predominantly affected muscles in SSN neurorrhaphy were the biceps brachii $(1.86 \pm 0.77)$ and infraspinatus $(1.86 \pm 0.66)$ muscles, followed by the subscapularis $(1.71 \pm 0.83)$ and supraspinatus (1.57 $\pm 0.65)$ muscles. In most cases, the predominant changes were grades 1 and 2 .

In the EEN group, pathological changes were discovered in the supraspinatus $(1.67 \pm 1.53)$, biceps brachii $(1.0 \pm 1.0)$, infraspinatus $(1.67 \pm 1.53)$ and subscapularis muscles $(1.67 \pm 0.58)$.

In the B group (no coaptation), the supraspinatus (3.33 \pm 0.58$)$, biceps brachii $(3.33 \pm 0.58)$, and infraspinatus $(3.33 \pm 0.58)$ muscles demonstrated the highest degrees of denervation. Minor changes were also found in the subscapularis muscles (median value of $1.33 \pm 1.15$ ).

The statistical analysis results for each group are presented in Table II.

\section{Histomorphometric analysis}

The numbers of myelinated axons were markedly reduced in the EEN, ESN and SSN groups compared with that in the C group; however, the numbers of myelinated axons were increased in the EEN, ESN and SSN groups compared with that in the B group. The largest axon diameters and myelin sheaths were observed in group C, followed by the EEN, SSN, and ESN groups. The ESN group had a higher G-ratio compared with the SSN group (Table III). The study groups showed statistically significant differences (MW $<0.001, p<0.01)$ in the following additional parameters: axon diameter, fiber diameter, myelin sheath thickness and the G-ratio, with the exception of the G-ratio in the EEN group compared with that in the ESN group ( $\mathrm{MW}=0.014, p<0.01$ ), the G-ratio in the ESN group compared with that in the $C$ group $(\mathrm{MW}=0.2368, p<0.01)$, and the G-ratio in the EEN group compared with that in the $C$ group $(\mathrm{MW}=$ $0.016, p<0.01)$. 
Table II. Electromyographic comparison among all the groups and the results of the reinnervation of the muscles. C group - control group, EEN - direct neurorrhaphy (end-to-end) group, ESN - end-to-side coaptation group, SSN - side-to-side coaptation group, B group - no coaptation

\begin{tabular}{|c|c|c|c|c|}
\hline & $\begin{array}{c}\text { Supraspinatus muscle } \\
(\mathrm{C} 5-\mathrm{C} 6)\end{array}$ & $\begin{array}{l}\text { Infraspinatus muscle } \\
\text { (C5-C6) }\end{array}$ & $\begin{array}{c}\text { Subscapularis muscle } \\
\text { (C6-C8) }\end{array}$ & $\begin{array}{c}\text { Biceps brachii muscle } \\
\text { (C5-C7) }\end{array}$ \\
\hline ESN vs. EEN ${ }^{*}$ & 0.831241 & 0.451858 & 0.563226 & 0.318075 \\
\hline ESN vs. $B^{*}$ & 0.002236 & 0.167138 & 0.924903 & 0.002236 \\
\hline ESN vs. $C^{* *}$ & $p<0.001$ & $p<0.001$ & $p<0.001$ & $p<0.001$ \\
\hline ESN vs. SSN ${ }^{*}$ & 0.905222 & 0.390024 & 0.29391 & 0.29479 \\
\hline SSN vs. EEN ${ }^{*}$ & 0.857655 & 0.723947 & 0.926405 & 0.11482 \\
\hline SSN vs. $B^{*}$ & 0.000578 & 0.070006 & 0.504925 & 0.007256 \\
\hline SSN vs. $C^{* *}$ & $p<0.001$ & $p<0.001$ & $p<0.001$ & $p<0.001$ \\
\hline EEN vs. $B^{*}$ & 0.151835 & 0.348641 & 0.677869 & 0.024896 \\
\hline EEN vs. $C^{\star *}$ & 0.085 & 0.085 & 0.009 & 0.085 \\
\hline B vs. $C^{* *}$ & $p<0.001$ & $p<0.001$ & $p<0.085$ & $p<0.001$ \\
\hline
\end{tabular}

"Student's t-test

"Mann-Whitney U test

Table III. Values of the following parameters in the experimental groups: nerve area $\left(\mathrm{mm}^{2}\right)$, nerve diameter $(\mathrm{mm})$, number of axons, myelin fiber density (fiber $\left./ \mathrm{mm}^{2}\right)$, minimal diameter of myelin fibers $(\mu \mathrm{m})$, minimal axon diameter $(\mu \mathrm{m})$, myelin area $\left(\mu \mathrm{m}^{2}\right)$, G-ratio axon/fiber diameter - axon diameter fiber. C group - control group, EEN - direct neurorrhaphy (end-to-end) group, ESN - end-to-side coaptation group, SSN - side-toside coaptation group, B group - no coaptation

\begin{tabular}{|lccccc|}
\hline & ESN & SSN & EEN & B & C \\
\hline $\begin{array}{l}\text { Number of axons/myelin fiber density } \\
\left(\text { fiber } / \mathrm{mm}^{2}\right)\end{array}$ & $170.14 \pm 3.71$ & $130.32 \pm 4.6$ & $209.96 \pm 3.6$ & $23.85 \pm 1.6$ & $362.14 \pm 2.83$ \\
\hline Myelin sheath $(\mu \mathrm{m})$ & $1.325 \pm 0.58$ & $1.552 \pm 0.72$ & $1.993 \pm 0.50$ & $1.390 \pm 0.49$ & $2.267 \pm 0.53$ \\
\hline G-ratio axon/fiber diameter & $0.6589 \pm 0.08$ & $0.6318 \pm 0.09$ & $0.6399 \pm 0.008$ & $0.552 \pm 0.10$ & $0.6559 \pm 0.08$ \\
\hline Axon diameter $(\mu \mathrm{m})$ & $5.531 \pm 3.10$ & $5.761 \pm 3.501$ & $7.630 \pm 3.173$ & $3.591 \pm 1.56$ & $9.049 \pm 2.86$ \\
\hline Fiber diameter $(\mu \mathrm{m})$ & $8.180 \pm 4.033$ & $8.864 \pm 4.613$ & $11.62 \pm 3.65$ & $6.371 \pm 2.12$ & $13.58 \pm 3.19$ \\
\hline
\end{tabular}

In all of the groups, the axons within the nerves were grouped into fascicles surrounded by perineural connective tissue (Fig. 2). The small- and large-diameter myelinated axons were evenly distributed in the nerves in the EEN and C groups. Smaller and closely packed myelinated axons were found in both the ESN and SSN groups. The distribution of myelinated axons in the ESN group was more similar to that in the EEN group than to that in the SSN group (Fig. 3). The differences in myelin sheath thickness were greater between the SSN and EEN groups than between the ESN and EEN groups. The frequency distribution of myelin sheath diameter revealed the presence of larger numbers of very small axons in both the EEN and ESN groups compared with the C group (Fig. 4).
Regression analysis revealed that the extent of axon remyelination was more advanced after EEN than after ESN or SSN. The myelin was thicker, and there was less individual scatter around the regression line, resulting in a decreased correlation coefficient and a decreased slope of the regression line of best fit (Fig. 5). Regression analysis showed a decrease in the myelin thickness of large-diameter fiber axons. This decrease was reflected by a slight decrease in the slope of the regression line of best fit (Fig. 6).

\section{Skin pinch test}

The spatial pattern of sensitivity recovery was identical in all of the groups; however, the recovery 

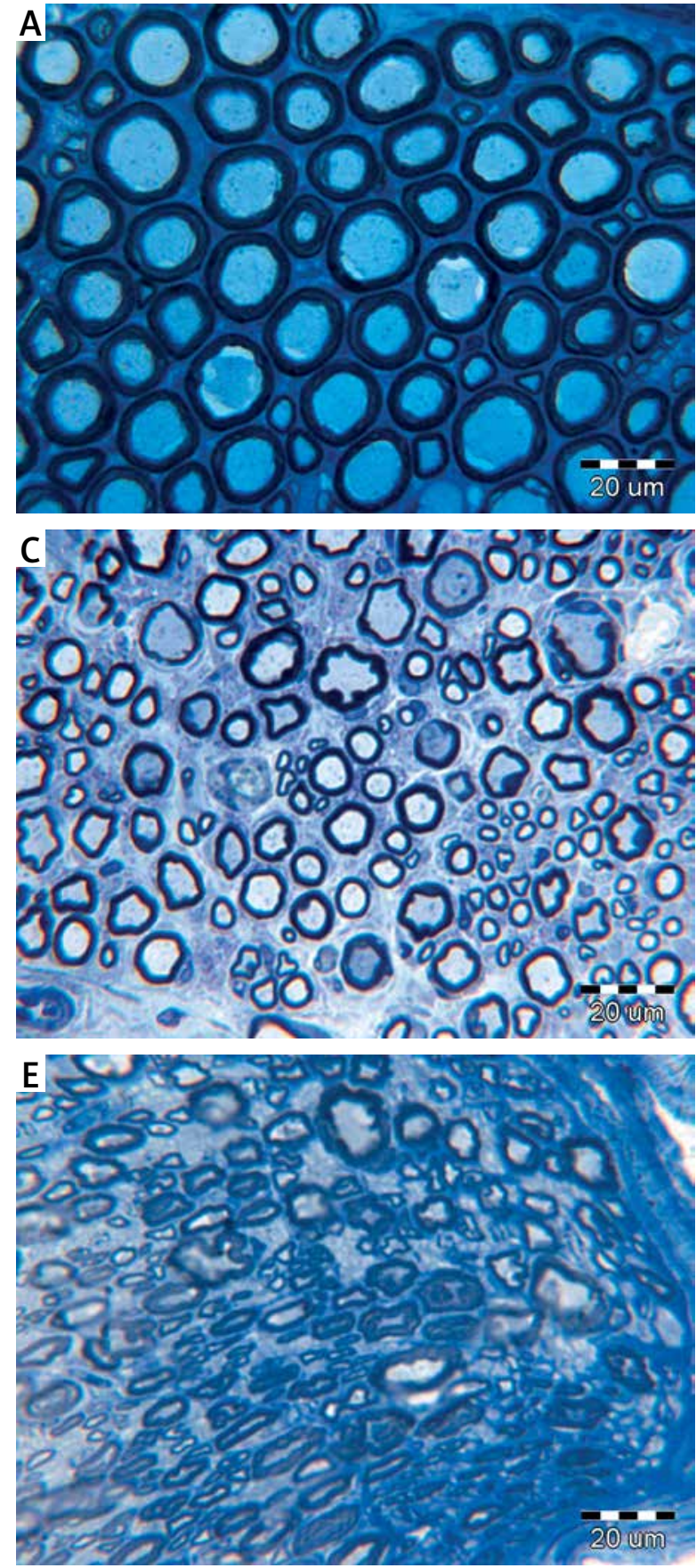

time and end results were different. Significant differences in these parameters were found between the ESN and control groups ( $t<0.01, p<0.05$ ), whereas no significant difference was observed between the ESN and EEN groups $(t=0.20, p>0.05)$. In addition, significant differences in these parameters were observed between the SSN group and both the $\operatorname{EEN}(t=0.01, p<0.05)$ and $C$ groups $(t<0.01$,
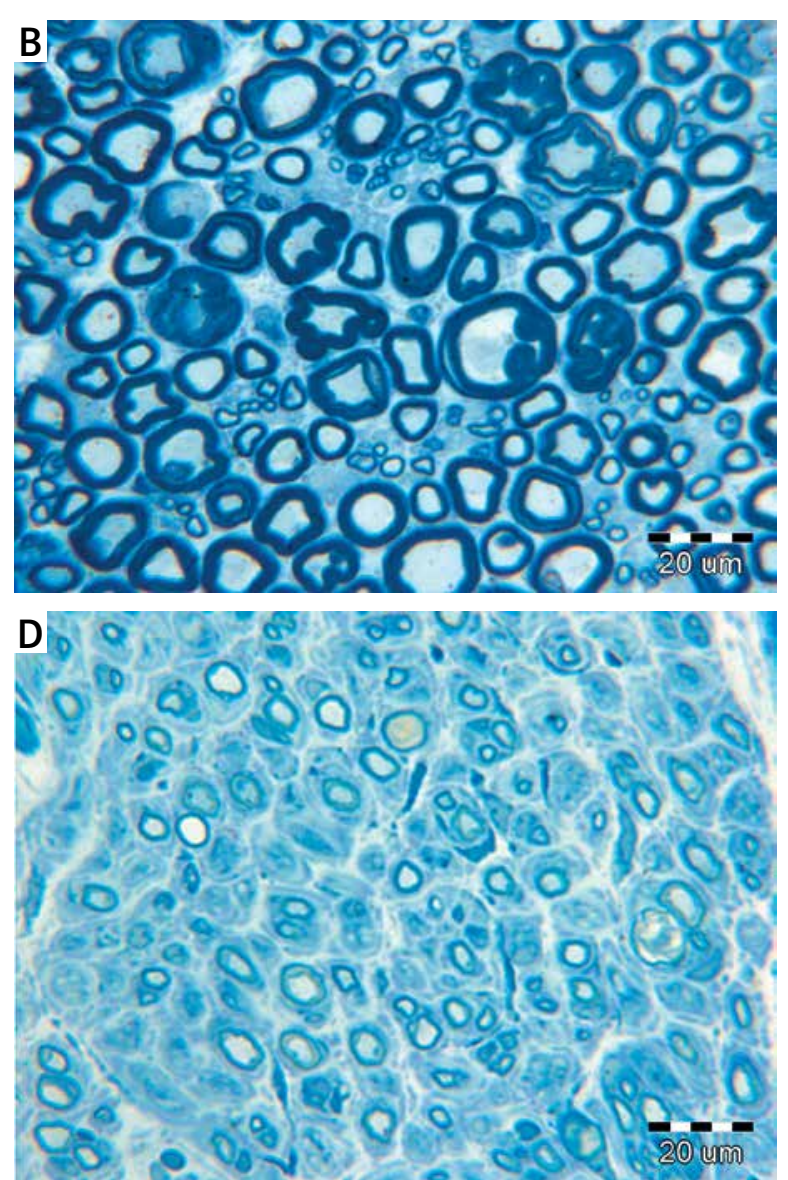

Fig. 2. Microscopic image of the sampled nerves (magnification $\times$ 630). Toluidine blue staining. A) C group (control group). B) Direct neurorrhaphy (end-to-end) (EEN) group. C) End-to-side coaptation (ESN) group. D) Side-to-side coaptation (SSN) group. E) B group (no coaptation). 
A

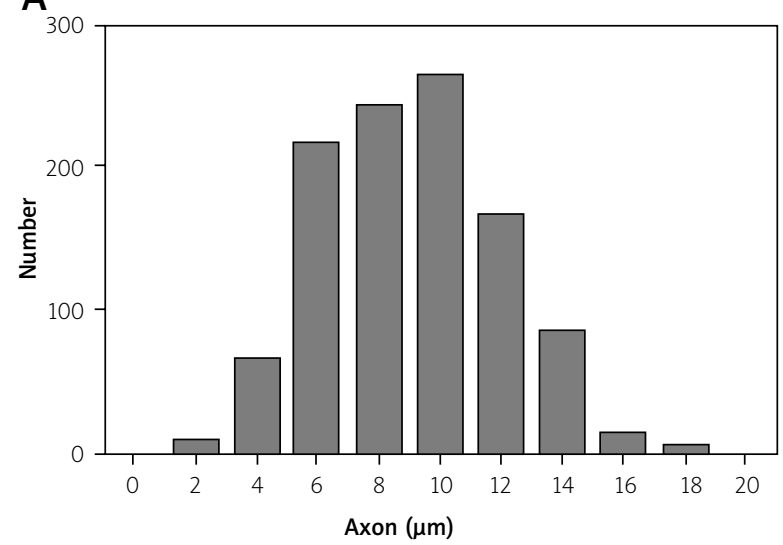

C

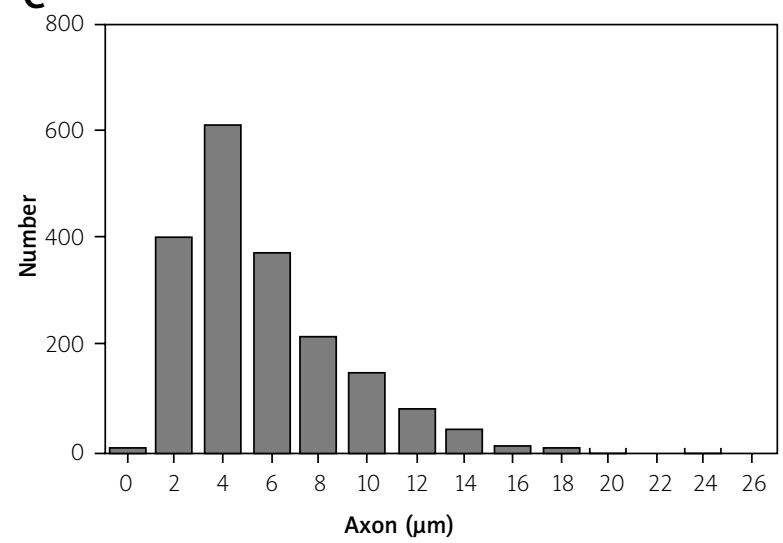

$\mathrm{E}$

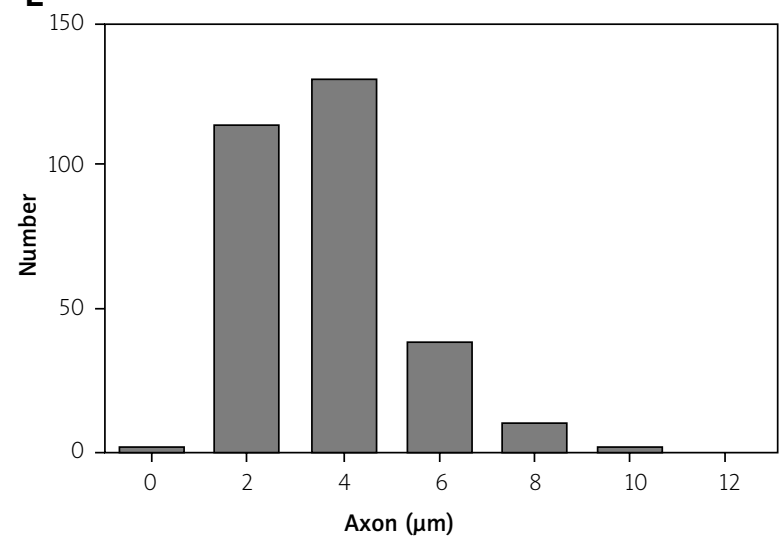

rabbits in group C, in all except for 1 rabbit in the EEN group, in all except for 1 rabbit in the ESN group, and in 4 rabbits in the SSN group, and negative results were obtained in all of the animals in the $B$ group. There were no significant differences between the ESN and $C$ groups $(t=0.08, p<0.05)$ or between the ESN and EEN groups $(t=0.62, p<0.05)$; however, the results after ESN were more similar to those after EEN.
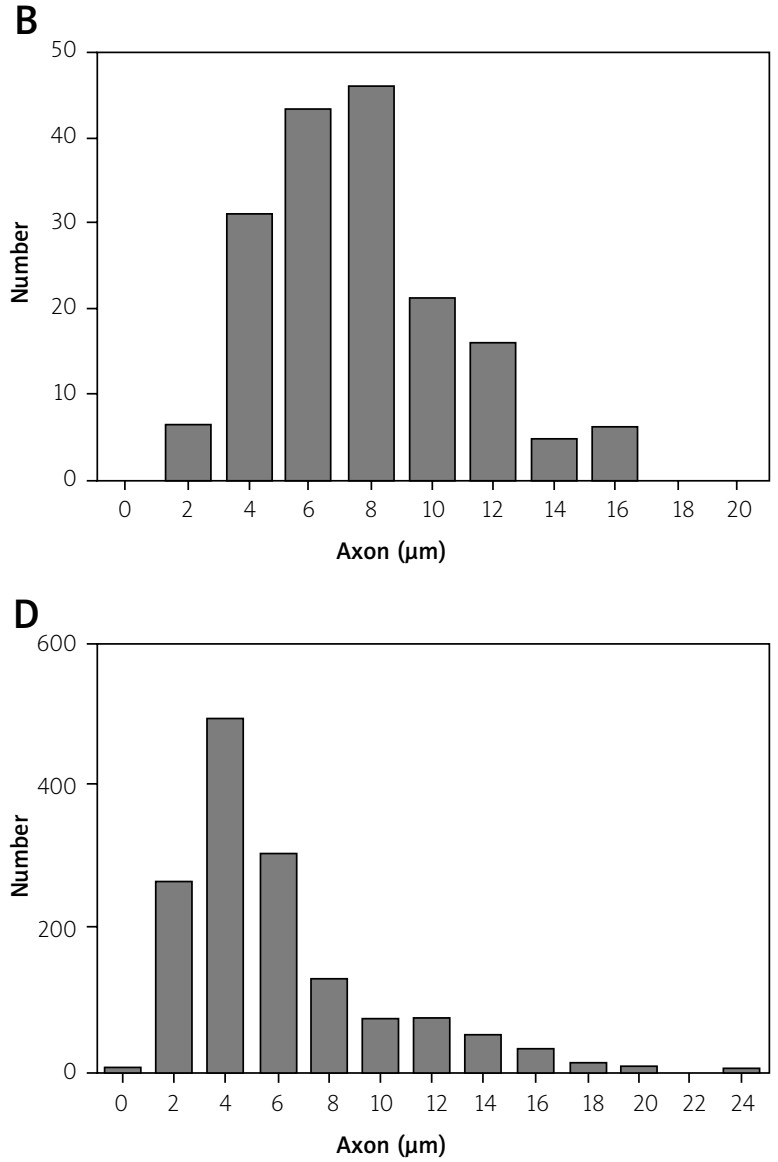

Fig. 3. Frequency distribution of the axon $(\mu \mathrm{m})$. A) $C$ group (control group). B) Direct neurorrhaphy (end-to-end) (EEN) group. C) End-to-side coaptation (ESN) group. D) Side-to-side coaptation (SSN) group. E) B group (no coaptation).

\section{Grooming test}

The movement of the forepaw toward the head after water spraying was analyzed, and the results indicated that there were no significant differences between the ESN and EEN groups $(t=0.12, p<0.05)$ in contrast with the significant differences observed between the ESN and $C$ groups $(t<0.01, p<0.05)$. Statistical analysis also revealed significant differences between the SSN and 
A

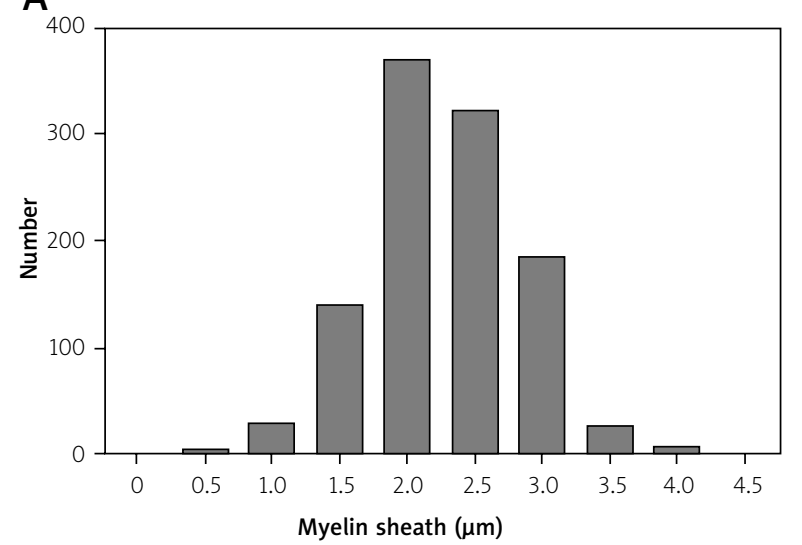

C

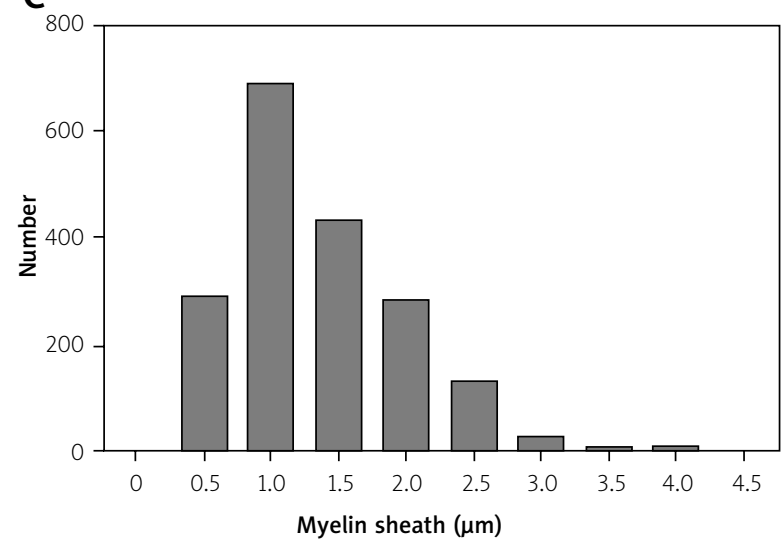

E

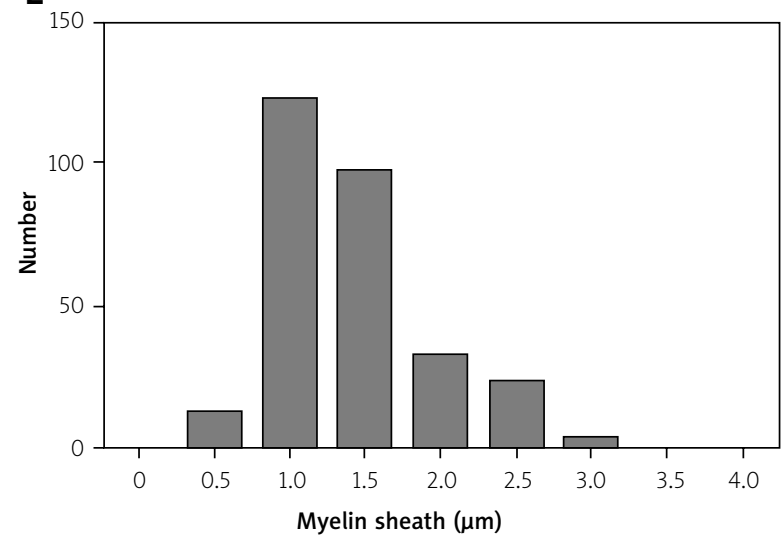

C groups $(t<0.01, p<0.05)$ and between the SSN and EEN groups $(t=0.04, p<0.05)$. The EEN group showed more rapid and better functional recovery compared with the ESN and SSN groups (Table IV).

\section{Discussion}

Recent studies of coaptation have shown very interesting results regarding synergistic motor nerve
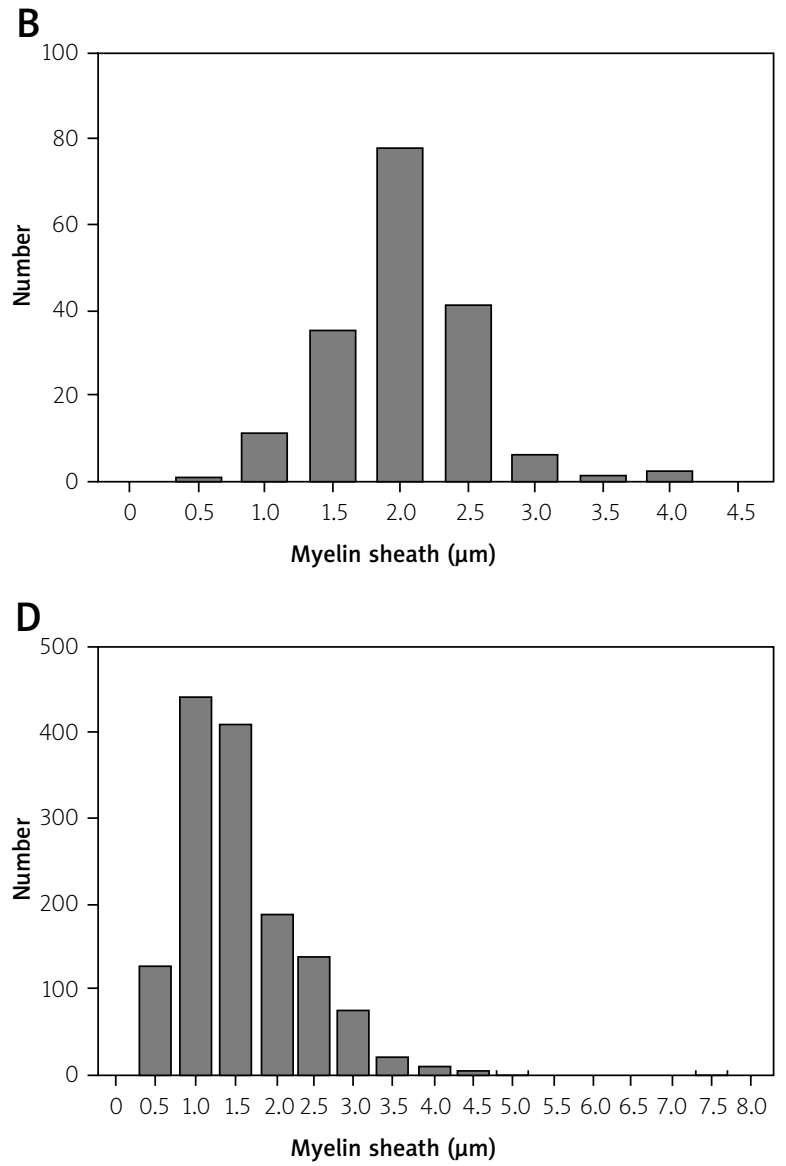

Fig. 4. Frequency distribution of the myelin sheath $(\mu \mathrm{m})$. A) C group (control group). B) Direct neurorrhaphy (end-to-end) (EEN) group. C) End-to-side coaptation (ESN) group. D) Sideto-side coaptation (SSN) group. E) B group (no coaptation).

fiber transfer between different nerves [48], end-toside neurorrhaphy by autonomic nerves and somatic nerves [19], and reverse end-to-side nerve transfer [28]. Additionally, a new type of cortical neuroplasticity after nerve repair of brachial plexus lesions has been described [6].

Although many coaptation studies have been performed, none have examined coaptation of the 
A

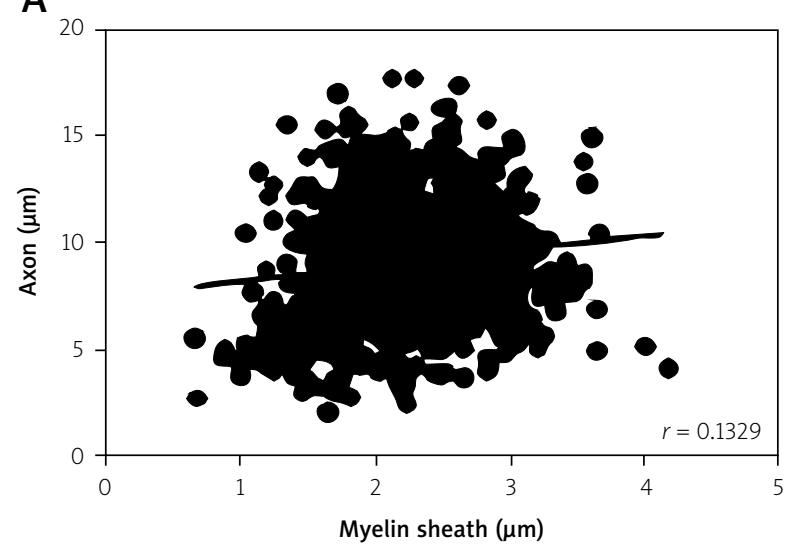

C

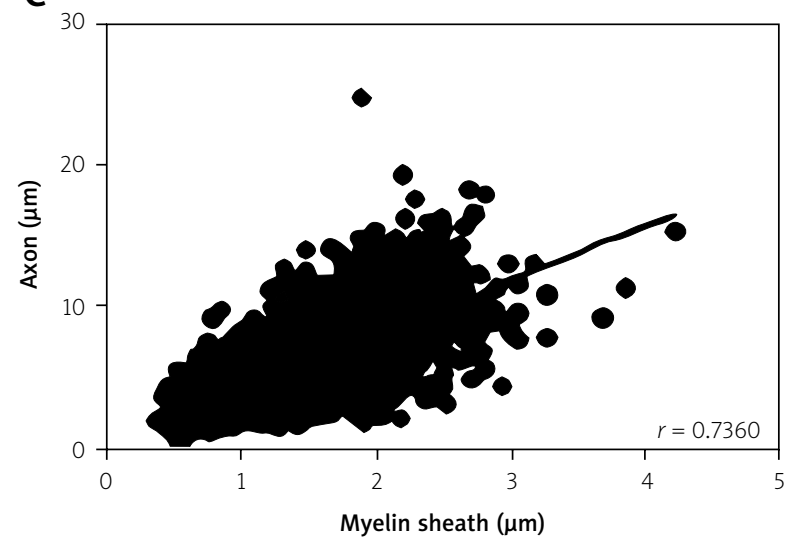

$\mathrm{E}$

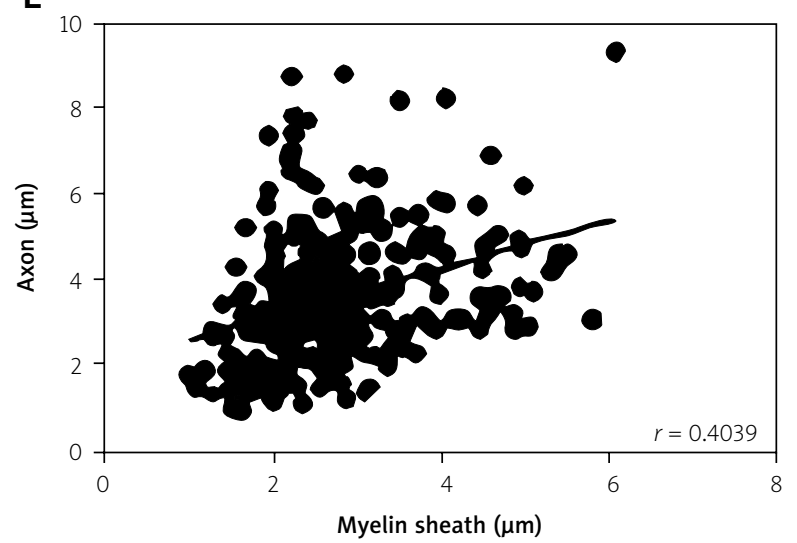

ventral branches of the spinal nerves or the trunks at the brachial plexus level. This lack of research might have resulted from differing views regarding the proximal or distal coaptation procedure or exploitation of the intraplexus or extraplexus nerves. This topic is controversial, and it has been difficult to find a research model that enables reliable nerve assessment after a coaptation proce-
B

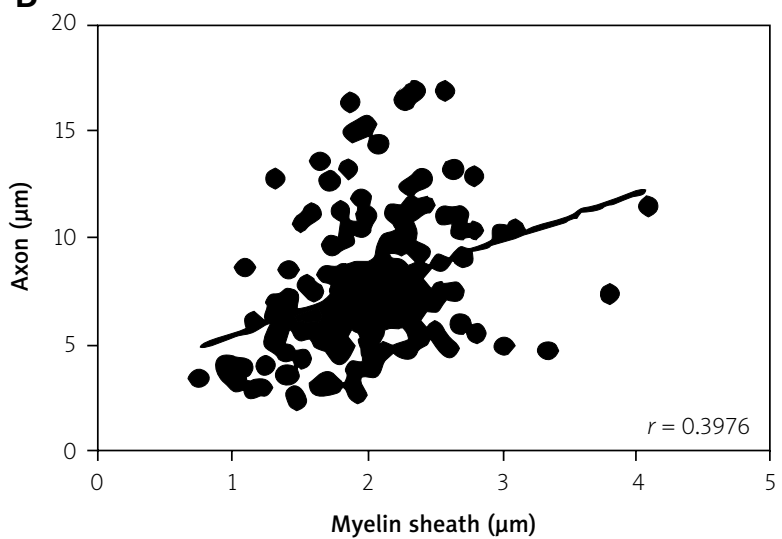

D

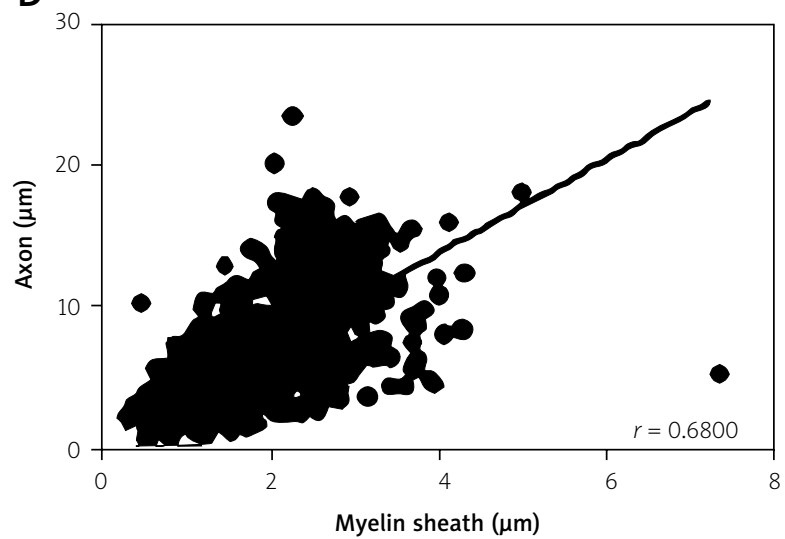

Fig. 5. Regression analysis of the relationship between the axon diameter $(\mu \mathrm{m})$ and the myelin sheath $(\mu \mathrm{m})$. $\mathrm{R}$ - regression coefficient. A) C group (control group). B) Direct neurorrhaphy (endto-end) (EEN) group. C) End-to-side coaptation (ESN) group. D) Side-to-side coaptation (SSN) group. E) B group (no coaptation). dure. Additionally, the examination results have not been encouraging in cases in which the peripheral nerves correspond to different segments of the spinal cord or in which mixed nerves are used as donors.

We selected a central coaptation model for use in our study, similar to Bentolia [7]. Our results indicated that a better outcome could be attained by 
A

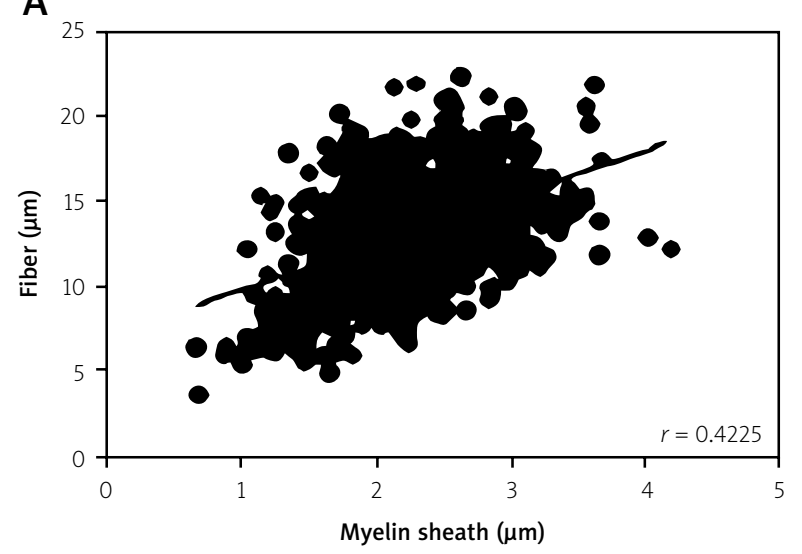

C

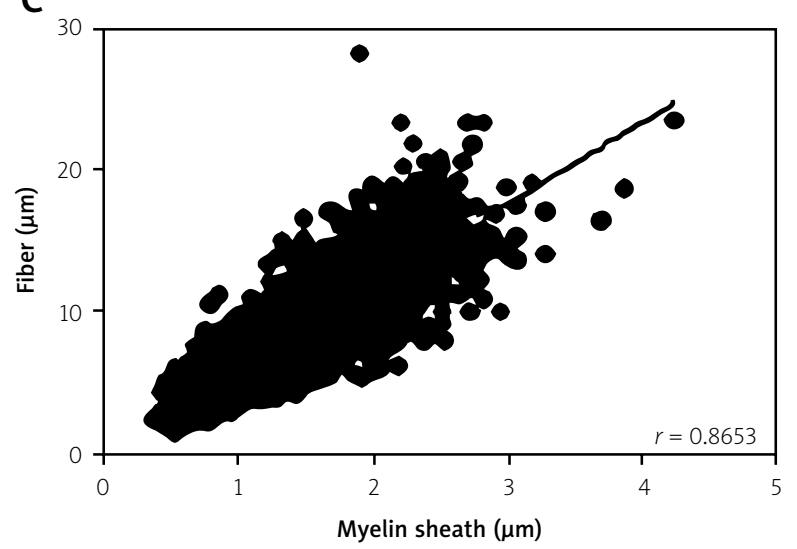

E

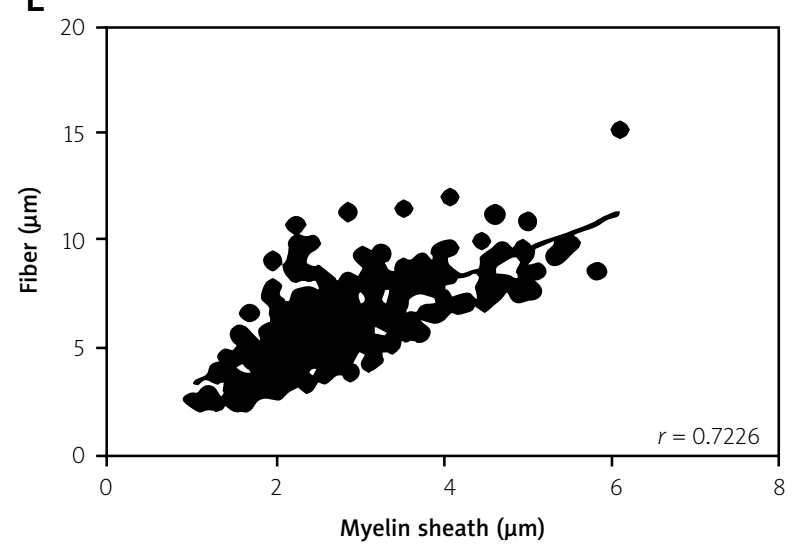

coapting grafts distal to the lateral or posterior cord to achieve more distal coaptation near the distal objective (i.e., the musculocutaneous nerve). On the other hand, Alnot [3] and Terzis [55] have reported that the use of nerve grafts is more successful when coapting nerve grafts distal to the peripheral nerve rather than distal to the proximal plexus elements (i.e., the cords). At this point most of the nerve fibers
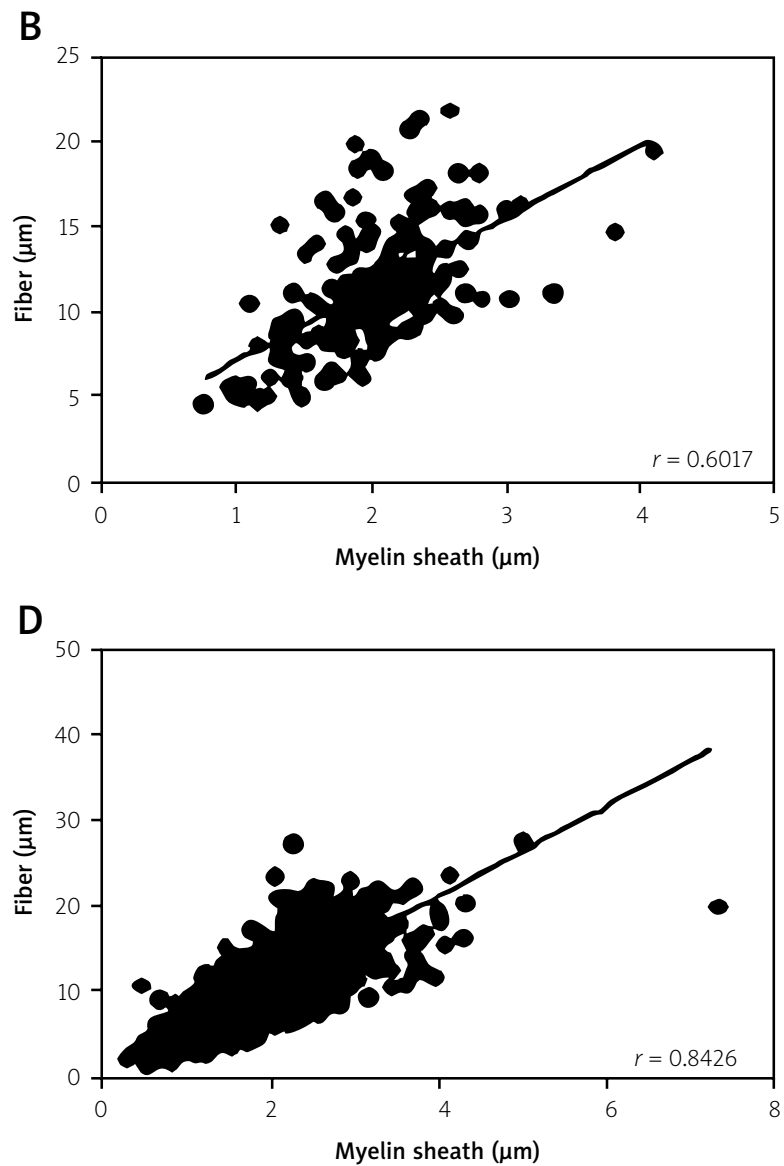

Fig. 6. Regression analysis of the relationship between the fiber diameter $(\mu \mathrm{m})$ and the myelin sheath $(\mu \mathrm{m})$. R-regression coefficient. A) C group (control group). B) Direct neurorrhaphy (endto-end) (EEN) group. C) End-to-side coaptation (ESN) group. D) Side-to-side coaptation (SSN) group. E) B group (no coaptation). would not be lost in fortuitous reinnervation, which would result in achievement of the desired goal.

When a donor is used, many authors [2,42] have preferred to apply intraplexus motor donors for neurotization when they are available because doing so yields better results. In our study, we applied intraplexus motor donors because we agree that intraplexus donors have a greater number of axons than 
Table IV. Assessment of the return of sensation (skin pinch test) to the dermatomes and results of the grooming test. EEN - direct neurorrhaphy (end-to-end) group, ESN - end-to-side coaptation group, SSN - side-to-side coaptation group. C5, C6, C7 - ventral branches of spinal nerves C5, C6, C7

\begin{tabular}{|lllllccc|}
\hline & & 4 weeks & 8 weeks & 12 weeks & 16 weeks & 20 weeks & 24 weeks \\
\hline $\begin{array}{l}\text { Dermatomes } \\
\text { C5-C6 }\end{array}$ & EEN & $0.5 \pm 0.5$ & $0.8 \pm 0.4$ & $2.1 \pm 0.4$ & $2.5 \pm 0.5$ & $2.5 \pm 0.5$ & $2.7 \pm 0.5$ \\
\cline { 2 - 8 } & ESN & $0.2 \pm 0.4$ & $0.2 \pm 0.4$ & $0.8 \pm 0.4$ & $1.4 \pm 0.5$ & $2.1 \pm 0.4$ & $2.3 \pm 0.5$ \\
\cline { 2 - 8 } & SSN & $0.1 \pm 0.2$ & $0.1 \pm 0.2$ & $0.6 \pm 0.5$ & $1.3 \pm 0.5$ & $1.7 \pm 0.4$ & $1.9 \pm 0.5$ \\
\hline $\begin{array}{l}\text { Dermatomes } \\
\text { C6-C7 }\end{array}$ & EEN & $1.7 \pm 0.5$ & $2.5 \pm 0.5$ & $2.8 \pm 0.4$ & 3 & 3 & 3 \\
\cline { 2 - 8 } & ESN & $1.5 \pm 0.5$ & $1.9 \pm 0.3$ & $2.1 \pm 0.4$ & $2.5 \pm 0.5$ & $2.8 \pm 0.4$ & 3 \\
\hline $\begin{array}{l}\text { Dermatomes } \\
\text { C7-C8-Th1 }\end{array}$ & ESN & $1.4 \pm 0.5$ & $1.6 \pm 0.5$ & $1.9 \pm 0.3$ & $2.1 \pm 0.4$ & $2.2 \pm 0.4$ & $2.2 \pm 0.4$ \\
\cline { 2 - 7 } & ESN & $1.4 \pm 0.5$ & $1.9 \pm 0.3$ & 3 & 3 & 3 & 3 \\
\hline SSN & $0.7 \pm 0.4$ & $1.1 \pm 0.3$ & 3 & 3 & 3 & 3 \\
\hline Grooming test & EEN & $2.3 \pm 0.5$ & $3.3 \pm 0.5$ & $3.7 \pm 0.5$ & $3.9 \pm 0.4$ & $4.1 \pm 0.4$ & $4.3 \pm 0.5$ \\
\cline { 2 - 7 } & ESN & $1.4 \pm 0.5$ & $1.9 \pm 0.3$ & $2.6 \pm 0.5$ & $3.2 \pm 0.4$ & $3.6 \pm 0.5$ & $3.9 \pm 0.5$ \\
\cline { 2 - 7 } & SSN & $0.7 \pm 0.4$ & $1.1 \pm 0.3$ & $1.8 \pm 0.4$ & $2.4 \pm 0.4$ & $3.0 \pm 0.3$ & $3.7 \pm 0.4$ \\
\hline
\end{tabular}

extraplexus donors; thus, the likelihood of successful neurotization is greater. The use of extraplexus nerves was reserved for specific uses for particular targets (e.g., the shoulder and elbow).

The indications for the C7 spinal nerve, which is characterized as a mixed nerve, are controversial, and the surgical results might be difficult to predict $[29,30,43]$. However, new coaptation strategies have been developed $[6,19,28,48]$.

Interestingly, coaptation involving extension of the probable epineurium or perineurial opening has been performed by many authors. Regarding the surgical technique, we elected to open the epineurium of the donor to expose it to the coapted recipient nerve, as previously described by Viterbo [58] and Lundborg [37]. Although terminolateral nerve regeneration could occur without any surface lesions on the donor nerve [27], experimental research has shown that regeneration is superior when a window is opened in the donor nerve [23,37]. It is widely accepted that resection of a small part of the epineurium improves the efficacy of end-to-side coaptation. Other research has demonstrated that resection of the deeper connective layers of the nerve (the perineurium) further increases the efficacy of terminolateral reconstruction $[25,35,61]$.

We found statistically significant differences in all parameters except for the G-ratio in a comparison of the ESN group with the control group. These similar G-ratios might indicate the possibility of regeneration of myelinated fibers; however, the much smaller amount of these fibers did not allow for conduction to occur, as observed in the control group. This failure might have been the result of scar tissue compression, leading to smaller axons. On the other hand, nerve regeneration was observed in the ESN group, confirming the significant differences compared with the no coaptation group. The ESN and EEN groups did not significantly differ in the EMG examination results $(t=0.39, p<0.05)$, with respect to the G-ratio (MW $=0.014, p<0.01)$, the grooming test results $(t=$ $0.12, p<0.05)$, the nerve pinch test results $(t=0.62$, $p<0.05)$ or the skin pinch test results $(t=0.20, p<$ $0.05)$. These findings indicate that similar functional results were obtained for both methods; however, these findings were not found to be correlated with the histomorphometric measurements.

The electrophysiological data for end-to-side coaptation indicated that the axons in the coapted nerves displayed different characteristics from those of intact nerves; however, they were able to induce good functional reinnervation. This phenomenon was most likely caused by the relatively large numbers of thicker axons and thin myelin sheaths.

The SSN group showed statistically significant differences in all parameters compared with both 
the control and no coaptation groups. These results were interpreted as much worse outcomes compared with those observed in the $C$ group; however, they indicated the possibility of nerve regeneration. In addition, the lack of statistically significant differences ( $t=0.85, p<0.05$ ) in the EMG examination results and the statistically significant differences in the G-ratio and histomorphometric measurements in the SSN group compared with the EEN group showed that the SSN method was less effective than the EEN method. The lower G-ratio and the decreased number of myelinated fibers in the SSN group might indicate a very small possibility of regeneration by collateral sprouting.

In our study, we used the end-to-side and sideto-side methods. The anatomical conditions (short spinal nerves and wide perimeters) in some cases (after confirmation of the efficiency of the method in consecutive experimental examinations) necessitated side-to-side coaptation.

In addition, encouraging results on the application of side-to-side coaptation as a complementary technique have been presented by Arm [4] and Shea [50], who observed reduced muscle atrophy with a side-to-side nerve bridge combined with traditional end-to-end neurorrhaphy.

The lack of significant findings for the subscapularis muscle could be explained by the fact that this muscle was also innervated by the ventral branches of the C7 and C8 spinal nerves, which induced partial function. In the biceps brachii muscle, the significant differences in the maintenance of lower amplitudes could be explained by the fact that the connected branches between C5/C6 and C7 were cut and the biceps muscle was deprived of stimulation from the ventral branches of the C5 and C6 spinal nerves.

The number of myelinated axons in the ESN group was $47 \%$ of that in the control group. This finding is similar to that of Fogotti, who reported that the mean number of nerve fibers was significantly higher in a control group compared with an ESN group [21]. This finding is also comparable to those of other studies describing end-to-side coaptation. For example, approximately $50-65 \%$ of the original axons have been reported to be retained in the recipient nerve by coaptation between the peroneal and tibial nerves $[34,47,62]$. The results of this study showed that the number of myelinated axons present in recipient nerves in the ESN group was $81 \%$ of that in the EEN group.
Similar results have been reported by Gao, who performed a clinical trial, finding that end-to-side coaptation resulted in a significant decrease in myelinated axons by $53 \%$ compared with a control group [22].

As previously reported $[15,45]$, the G-ratio in the central nerves of rats is near 0.7 , and it is more than 0.6 in the peripheral nerves. For rabbits, this ratio is 0.59-0.63 at the root level, 0.62-0.65 at the trunk level, and 0.63 in the suprascapular nerve [44]. Comparison of these results with those obtained using healthy limbs appears to be sufficient to assess conduction ability. The G-ratio indicates the possibility of conduction; however, the presence of fewer myelinated axons was responsible for the weaker final results. More rapid and better functional recovery occurred in the EEN group because EEN is involved in the regeneration of axotomized nerves, whereas ESN is involved in the collateral sprouting of intact nerves [1,34].

In the case of end-to-side coaptation, regenerated axons appear from the Ranvier nodes of the donor nerve most proximal to the coaptation site, and it is guided into the epineurium of the donor nerve $[27,61]$. Before axonal development, Schwann cells are organized into columns at the coaptation site [52]. Then, these cells invade the epineurial layer of the recipient nerve [38]. This is the most important stage in the phenomenon of collateral sprouting [38]. Axons appear from Ranvier nodes of the donor nerve proximal to the site of coaptation [53]. Schwann cells stimulate axonal regeneration from both the distal nerve stump and the nodes of Ranvier of the donor nerve [54, 56]. This mechanism is indirectly controlled by neurotropic factors [61]. After these factors are released from Schwann cells by diffusion, they penetrate through the epineurium into the perineurium. In this way, directed collateral sprouting from the region closest to the injury site occurs at the Ranvier nodes of the donor nerve [61].

Axotomy results in injury to the motor neurons and quickly triggers axonal regeneration; however, in the case of ESN, humoral factors released by damaged or degenerating recipient nerves are likely to play roles in the sprouting of intact donor axons [8].

A linear relationship exists between myelin sheath thickness and axon diameters in nerves at maturity; however, this relationship deviates from the norm in regenerated nerves, depending on the 
axonal myelination pattern [15]. The slope of the regression line for regenerated nerves has been demonstrated to be lower than normal because of the myelin-axonal disproportion that persists for a period of time after intervention of regenerated axons that have failed to reinnervate a target [15].

The axon diameter and myelin thickness of the suprascapular nerve after repair and the regression analysis results suggested that the axons were not maximally myelinated. The slightly better parameters observed with EEN and ESN might have resulted from faster regeneration and more advanced myelination of axons; however, long-term studies are needed to determine whether these factors result in a better outcome.

The histological results differed from the behavioral results [48]. Morphological and functional examinations revealed that a limited number of motor axons were capable of producing adequate functional reinnervation of muscles.

The presented results indicate that sensory reinnervation is more effective than motor reinnervation. It has been suggested that it is easier to accomplish sensory reinnervation compared with motor reinnervation after end-to-side nerve repair [35,54]. It is possible that the earlier completion of sensory reinnervation compared with motor reinnervation observed in our study occurred because sensory axons are more prone to sprouting into end-to-side coapted nerves $[10,54]$ and they sprout at a faster rate compared with motor axons [29].

Although consecutive analyses have emphasized the efficacy of coaptation in practice, the underlying mechanism remains to be elucidated. This mechanism is the outcome of the coaptation technique and complex molecular processes.

The most important molecule involved in this process is neurotrophin-3 (NT-3) [53], which acts through its receptor Trk C, followed by growth-associated protein-43 (GAP-43), a marker of growth cone formation, brain-derived neurotrophic factor (BDNF) and Trk B (BDNF receptor) [60]. Another important factor affecting collateral sprouting is nerve growth factor (NGF) [5,51]. NGF is produced in end organs following nerve injury. It is taken up by axon terminals and transported retrogradely to the nerve cell body, stimulating a secondary response. NGF and ciliary neurotrophic factor (CNTF) facilitate axonal regeneration after end-to-side neurorrhaphy [39]. The regulation of matrix metalloproteinase (MMP) expression and activity [20] as well as neurotrophic factors (TIMPs and IGF) $[12,40]$ might also have very important roles in this process. Recent experimental studies have shown that physical and chemical agents stimulate nerve regeneration after end-toside coaptation, including phototherapy, FK506, and acetyl-L-carnitine [13,24,32,57].

Our results demonstrate the effectiveness of ESN; however, they should be confirmed by retrograde labeling. The main limitation lies in the translation of laboratory results to the clinical setting, which represents a critical step in biomedical research. Unfortunately, promising basic science and preclinical results sometimes fail to meet expectations when they are applied clinically $[17,23]$.

We believe that our results could aid in the development of a differential approach to nerve injury, depending on the nerve trunks involved, the location of the injury, and the methods of repair and reconstruction. We hope that the described method of coaptation, in addition to the neurotropic factors that have been identified, might be used to develop an alternative treatment to surgery of the brachial plexus.

\section{Conclusions}

The electrophysiological, histomorphometric and behavioral results obtained using end-to-side coaptation of ventral branches of the C5 and C6 spinal nerves to the $\mathrm{C} 7$ spinal nerve in the brachial plexi of rabbits confirm the occurrence of collateral sprouting at this level. After further research is performed to confirm the results of this study, end-to-side coaptation might emerge as an alternative method in the treatment of brachial plexus avulsion.

\section{Acknowledgments}

We thank Bartosz Witkowski, who provided medical writing service on behalf of Wroclaw Medical University.

\section{Disclosure}

Authors report no conflict of interest.

\section{References}

1. Akeda K, Hirata H, Matsumoto M, Fukuda A, Tsujii M, Nagakura T, Ogawa S, Yoshida T, Uchida A. Regenerating axons emerge far proximal to the coaptation site in end-to-side nerve coapta- 
tion without a perineurial window using a T-shaped chamber. Plast Reconstr Surg 2006; 117: 1194-1203.

2. Allieu Y, Privat JM, Bonnel F. Paralysis in root avulsion of the brachial plexus: neurotization by the spinal accessory nerve. Clin Plast Surg 1984; 11: 133-136.

3. Alnot J. Traumatic brachial plexus lesions in the adult. Indications and results. Hand Clin 1995; 11: 623-631.

4. Amr SM, Moharram AN. Repair of brachial plexus lesions by end-to-side side-to-side grafting neurorrhaphy: experience based on 11 cases. Microsurgery 2005; 25: 126-146.

5. Bajrović F, Kovacic U, Pavcnik M, Sketelj J. Interneuronal signalling is involved in induction of collateral sprouting of nociceptive axons. Neuroscience 2002; 111: 587-596.

6. Beisteiner R, Höllinger I, Rath J, Wurnig M, Hilbert M, Klinger N, Geissler A, Fischmeister F, Wöber C, Klösch G, Millesi H, Grisold W, Auff E, Schmidhammer R. New type of cortical neuroplasticity after nerve repair in brachial plexus lesions. Arch Neurol 2011; 68: 1467-1470.

7. Bentolia V, Nizard R, Bizot P, Sedel L. Complete traumatic brachial plexus palsy. Treatment and outcome after repair. J Bone Joint Surg Am 1999; 81: 20-28.

8. Beris A, Lykissas M, Korompilias A, Mitsionis G. End-to-side nerve repair in peripheral nerve injury. J Neurotrauma 2007; 24: 909-916.

9. Bonham C, Greaves I. Brachial plexus injuries. Trauma 2011; 13: 353-363.

10. Bontioti E, Kanje M, Lundborg G, Dahlin LB. End-to-side nerve repair in the upper extremity of rat. J Peripher Nerv Syst 2005; 10: 58-68.

11. Brunelli G, Monini L. Neurotization of avulsed roots of brachial plexus by means of anterior nerves of cervical plexus. Clin Plast Surg 1984; 11: 149-152.

12. Chang C, Werb Z. The many faces of metalloproteases: cell growth, invasion, angiogenesis and metastasis. Trends Cell Biol 2001; 11: 37-43.

13. Chen B, Song Y, Liu Z. Promotion of nerve regeneration in peripheral nerve by short-course FK506 after end-to-side neurorrhaphy. J Surg Res 2009; 152: 303-310.

14. Chen L, Gu YD. An experimental study of contralateral C7 root transfer with vascularized nerve grafting to treat brachial plexus root avulsion. J Hand Surg Br 1994; 19: 60-66.

15. Chomiak T, Hu B. What is the optimal value of the g-ratio for myelinated fibers in the rat CNS? A theoretical approach. PLoS One 2009; 4: e7754.

16. Chuang DC, Yeh MC, Wei FC. Intercostal nerve transfer of the musculocutaneous nerve in avulsed brachial plexus injuries: evaluation of 66 patients. J Hand Surg Am 1992; 17: 822-828.

17. Dahlin LB. Nerve injuries. Current Orthopaedics 2008; 22: 9-16.

18. De Sá JM, Mazzer N, Barbieri CH, Barreira AA. The end-to-side peripheral nerve repair. Functional and morphometric study using the peroneal nerve of rats. J Neurosci Methods 2004; 136: 45-53.

19. Dong C, Gao W, Jia R, Li S, Shen Z, Li B. Reconstruction of anorectal function through end-to-side neurorrhaphy by autonomic nerves and somatic nerve in rats. J Surg Res 2013; 180: e63-e71.
20. Dzwonek J, Rylski M, Kaczmarek L. Matrix metalloproteinases and their endogenous inhibitors in neuronal physiology of the adult brain. FEBS Lett 2004; 567: 129-135.

21. Fagotti de Almeida CE, Farina Junior JA, Colli BO. Morphometric and Functional Analysis of Axonal Regeneration after End-toend and End-to-side Neurorrhaphy in Rats. Plast Reconstr Surg Glob Open 2015; 3: e326.

22. Gao W, Liu Q, Li S, Zhang J, Li Y. End-to-side neurorrhaphy for nerve repair and function rehabilitation. J Surg Res 2015; 197: 427-435.

23. Geuna S, Papalia I, Tos P. End-to-side (terminolateral) nerve regeneration: a challenge for neuroscientists coming from an intriguing nerve repair concept. Brain Res Rev 2006; 52: 381-388.

24. Gigo-Benato D, Geuna S, de Castro Rodrigues A, Tos P, Fornaro M, Boux E, Battiston B, Giacobini-Robecchi MG. Low-power laser biostimulation enhances nerve repair after end-to-side neurorrhaphy: a double-blind randomized study in the rat median nerve model. Lasers Med Sci 2004; 19: 57-65.

25. Goheen-Robillard B, Myckatyn TM, Mackinnon SE, Hunter DA. End-to-side neurorrhaphy and lateral axonal sprouting in a long graft rat model. Laryngoscope 2002; 112: 899-905.

26. Gu YD, Zhang GM, Chen DS, Yan JG, Cheng XM, Chen L. Seventh cervical nerve root transfer from the contralateral healthy side for treatment of brachial plexus root avulsion. J Hand Surg $\mathrm{Br}$ 1992; 17: 518-521.

27. Hayashi A, Yanai A, Komuro Y, Nishida M, Inoue M, Seki T. Collateral sprouting occurs following end-to-side neurorrhaphy. Plast Reconstr Surg 2004; 114: 129-137.

28. Kale SS, Glaus SW, Yee A, Nicoson MC, Hunter DA, Mackinnon SE, Johnson PJ. Reverse end-to-side nerve transfer: from animal model to clinical use. J Hand Surg Am 2011; 36: 1631-1639.e2.

29. Kanje M, Arai T, Lundborg G. Collateral sprouting from sensory and motor axons into an end to side attached nerve segment. Neuroreport 2000; 11: 2455-2459.

30. Kelly EJ, Jacoby C, Terenghi G, Mennen U, Ljungberg C, Wiberg $M$. End-to-side nerve coaptation: a qualitative and quantitative assessment in the primate. J Plast Reconstr Aesthet Surg 2007; 60: 1-12.

31. Kimura J. Electrodiagnosis in diseases of nerve and muscle: Principles and Practice. 3rd ed. Oxford University Press, New York 2001.

32. Kostopoulos VK, Davis CL, Terzis JK. Effects of acetylo-L-carnitine in end-to-side neurorrhaphy: a pilot study. Microsurgery 2009; 29: 456-463.

33. Kovacic U, Tomsic M, Sketelj J, Bajrović FF. Collateral sprouting of sensory axons after end-to-side nerve coaptation - a longitudinal study in the rat. Exp Neurol 2007; 203: 358-369.

34. Liao WC, Chen JR, Wang YJ, Tseng GF. The efficacy of end-to-end and end-to-side nerve repair (neurorrhaphy) in the rat brachial plexus. J Anat 2009; 215: 506-521.

35. Liu K, Chen LE, Seaber AV, Goldner RV, Urbaniak JR. Motor functional and morphological findings following end-to-side neurorrhaphy in the rat model. J Orthop Res 1999; 17: 293-300.

36. Loy S, Bhatia A, Asfazadourian H, Oberlin C. Ulnar nerve fascicle transfer onto to the biceps muscle nerve in $\mathrm{C} 5-\mathrm{C} 6$ or $\mathrm{C} 5-\mathrm{C} 6-\mathrm{C} 7$ avulsions of the brachial plexus. Eighteen cases. Ann Chir Main Memb Super 1997; 16: 275-284. 
37. Lundborg G, Zhao Q, Kanje M, Danielsen N, Kerns JM. Can sensory and motor collateral sprouting be induced from intact peripheral nerve by end-to-side anastomosis? J Hand Surg Br 1994; 19: 277-282.

38. Lykissas MG. Current concepts in end-to-side neurorrhaphy. World J Orthop 2011; 2: 102-106.

39. McCallister WV, Tang P, Smith J, Trumble TE. Axonal regenera tion stimulated by the combination of nerve growth factor and ciliary neurotrophic factor in an end-to-side model. J Hand Surg Am 2001; 26: 478-488.

40. McFarlane S. Metalloproteases: carving out a role in axon guidance. Neuron 2003; 37: 559-562.

41. Moran SL, Steinmann SP, Shin AY. Adult brachial plexus injuries: mechanism, patterns of injury, and physical diagnosis. Hand Clin 2005; 21: 13-24.

42. Narakas AO, Hentz VR. Neurotization in brachial plexus injuries Indication and results. Clin Orthop Relat Res 1988; 237: 43-56.

43. Papalia I, Geuna S, Tos PL, Boux E, Battiston B, Stagno D'Alcontres F. Morphologic and functional study of rat median nerve repair by terminolateral neurorrhaphy of the ulnar nerve. J Reconstr Microsurg 2003; 19: 257-264.

44. Reichert P, Kiełbowicz Z, Dzięgiel P, Puła B, Kuryszko J, Gosk J, Bocheńska $A$. The rabbit brachial plexus as a model for nerve repair surgery - histomorphometric analysis. Anat Rec (Hoboken) 2015; 298: 444-454.

45. Rushton WA. A theory of the effects of fibre size in medullated nerve. J Physiol 1951; 115: 101-122.

46. Rutowski R. Neurotizations by means of the cervical plexus in over 100 patients with from one to five root avulsions of the brachial plexus. Microsurgery 1993; 14: 285-288.

47. Sanapanich K, Morrison WA, Messina A. Physiologic and morphologic aspects of nerve regeneration after end-to-end or end-to-side coaptation in a rat model of brachial plexus injury. J Hand Surg Am 2002; 27: 133-142.

48. Schmidhammer R, Nógrádi A, Szabó A, Redl H, Hausner T, van der Nest DG, Millesi $\mathrm{H}$. Synergistic motor nerve fiber trans fer between different nerves through the use of end-to-side coaptation. Exp Neurol 2009; 217: 388-394.

49. Schmidhammer R, Redl H, Hopf R, van der Nest DG, Millesi $H$. End-to-side nerve graft repair based on synergistic peripheral terminal motor branches: investigation in a nonhuman primate model. Eur Surg 2005; 37: 308-316.

50. Shea JE, Garlick JW, Salama ME, Mendenhall SD, Moran LA, Agarwal JP. Side-to-side nerve bridges reduce muscle atrophy after peripheral nerve injury in a rodent model. J Surg Res 2014 187: 350-358.

51. Shen $H$, Chung JM, Chung K. Expression of neurotrophin mRNAs in the dorsal root ganglion after spinal nerve injury. Brain Res Mol Brain Res 1999; 64: 186-192.

52. Slack JR, Hopkins WG, Williams MN. Nerve sheaths and motoneurone collateral sprouting. Nature 1979; 282: 506-507.

53. Sterne GD, Coulton GR, Brown RA, Green CJ, Terenghi G. Neurotrophin-3-enhanced nerve regeneration selectively improves recovery of muscle fibers expressing myosin heavy chains $2 b$. J Cell Biol 1997; 139: 709-715.

54. Tarasidis G, Watanabe O, Mackinnon SE, Strasberg SR, Haughey $\mathrm{BH}$, Hunter DA. End-to-side neurorraphy: a long-term study of neural regeneration in a rat model. Otolaryngol Head Neck Surg 1998; 119: 337-341.

55. Terzis JK, Vekris MD, Soucacos PN. Outcomes of brachial plexus reconstruction in 204 patients with devastating paralysis. Plast Reconstr Surg 1999; 104: 1221-1240.

56. Torigoe K, Tanaka HG, Takahashi A, Hashimoto K. Early growth of regenerating neurites in acrylamide neuropathic mice: application of a film model. Brain Res 1997; 746: 269-274.

57. Tos P, Colzani G, Ciclamini D, Titolo P, Pugliese P, Artiaco S. Clinical applications of end-to-side neurorrhaphy: an update. Biomed Res Int 2014; 2014: 646128.

58. Viterbo F, Trindade JC, Hoshino K, Mazzoni Neto A. Latero-terminal neurorrhaphy without removal of the epineural sheath. Experimental study in rats. Rev Paul Med 1992; 110: 267-275.

59. Xiong G, Ling L, Nakamura R, Sugiura Y. Retrograde tracing and electrophysiological findings of collateral sprouting after endto-side neurorrhaphy. Hand Surg 2003; 8: 145-150.

60. Yamauchi T, Maeda M, Tamai S, Tamai M, Yajima H, Takakura Y, Haga S, Yamamoto $\mathrm{H}$. Collateral sprouting mechanism after end-to-side nerve repair in the rat. Med Electron Microsc 2000; 33: 151-156.

61. Zhang Z, Johnson EO, Vekris MD, Zoubos AB, Bo J, Beris AE, Soucacos PN. Long-term evaluation of rabbit peripheral nerve repair with end-to-side neurorrhaphy in rabbits. Microsurgery 2006; 26: 262-267.

62. Zhang Z, Soucacos PN, Bo J, Beris AE. Evaluation of collateral sprouting after end-to-side nerve coaptation using a fluorescent double-labeling technique. Microsurgery 1999; 19: 281-286. 